\title{
An Improved Classification System for Brain Tumours Using Wavelet Transform and Neural Network
}

\author{
AS Dhas ${ }^{1}$, M Madheswaran ${ }^{2}$
}

\begin{abstract}
This paper presents an improved classification system for brain tumours using wavelet transform and neural network. The anisotropic diffusion filter was used for image denoising, and the performance of the oriented rician noise reducing anisotropic diffusion (ORNRAD) filter was validated. The segmentation of the denoised image was carried out by fuzzy c-means clustering. The features were extracted using symlet and coiflet wavelet transforms, and the Levenberg-Marquardt algorithm based neural network was used to classify the magnetic resonance (MR) images. This classification technique of MR images was tested and analysed with existing methods, and its performance was found to be satisfactory with a classification accuracy of $93.24 \%$. The developed system could assist physicians in classifying MR images for better decision-making.
\end{abstract}

Keywords: Brain tumour, fuzzy c-means, Levenberg-Marquardt algorithm, magnetic resonance images, neural network, wavelet transform

\section{Un sistema de clasificación mejorado para los tumores cerebrales usando la transformada de ondeletas y la red neuronal}

\author{
AS Dhas ${ }^{1}$, M Madheswaran ${ }^{2}$
}

\begin{abstract}
RESUMEN
Este articulo presenta un sistema de clasificación mejorado para los tumores de cerebro usando la transformada de ondeletas (transformada wavelet) y la red neuronal. El filtro de difusión anisotrópica fue utilizado para la eliminación del ruido de la imagen, y se validó el funcionamiento del filtro de difusión anisotrópica orientado a reducir el ruido riciano (ORNRAD, siglas en inglés). La segmentación de la imagen 'desruidizada'(denoised) fue realizada mediante el agrupamiento difuso c-means fuzzy. Las características fueron extraídas usando las transformadas de ondeletas symlet y coiflet, y la red neuronal basada en el algoritmo de Levenberg-Marquardt fue utilizada para clasificar las imágenes de resonancia magnética (RM) imágenes. Esta técnica de clasificación de imágenes de RM fue probada y analizada con métodos existentes, y se halló que su rendimiento era satisfactorio con una precisión de clasifi-
\end{abstract}

From: ${ }^{1}$ Department of Electronics and Communication Engineering, Vimal Jyothi Engineering College, Chemperi, Kannur, 670632, India and ${ }^{2}$ Centre for Research in Signal and Image Processing, Mahendra Engineering College, Mallasamudram, 637503, India.
Correspondence: Dr AS Dhas, Department of Electronics and Communication Engineering, Vimal Jyothi Engineering College, Chemperi, Kannur, 670632, India. Email: anto5751@gmail.com 
cación de 93.24\%. El sistema desarrollado podría ayudar a los médicos a clasificar imágenes de RM para una mejor toma de decisiones.

Palabras clave: Tumor cerebral, fuzzy c-means, algoritmo de Levenberg-Marquardt, imágenes de resonancia magnética, red neuronal, transformada de ondeletas

West Indian Med J 2018; 67 (3): 244

\section{INTRODUCTION}

In recent years, brain tumours have been found to be one of the leading causes of deaths, irrespective of age (1). With the advancement of imaging and image processing techniques, it is expected that more information will be provided to physicians to make accurate decisions for better healthcare. Brain tumours can be detected using any one of the imaging modalities and processed using image processing tools for accurate classification of tumours. Many researchers have reported various preprocessing algorithms, feature extraction techniques and classification algorithms (2-11).

A multi-resolution texture model consisting of treestructured wavelet transform (WT) was proposed by Celik and Tjahjadi for the texture analysis (2). The treestructured WT was developed as an adaptive scheme to regulate the channels that need sufficient decomposition. For instance, the binomial quadrature mirror filter (QMF) WT for multi-resolution signal decomposition was proposed by Akansu et al (3). This kind of binomial QMF performs more superior on test images than the conventional discrete cosine transform. The most integral component of neuroimaging analysis is the accurate classification of magnetic resonance (MR) images of the brain. With that concern, Zhang et al proposed the forward neural network to accurately classify the MR images as normal and abnormal (4). The parameters for feature extraction and classification were optimized using adaptive chaotic particle swarm optimization. The problem of choosing the appropriate feature extraction and prediction algorithm for the classification of MR images of the brain still remains. With that concern, this paper proposed a combined approach of WT and neural network for efficient classification of MR images of the brain.

\section{MATERIAL AND METHODS}

Figure 1 shows the general workflow for the classification process. The test MR images underwent a set of processes: pre-processing, segmentation, feature extraction and classification of MR images of the brain.

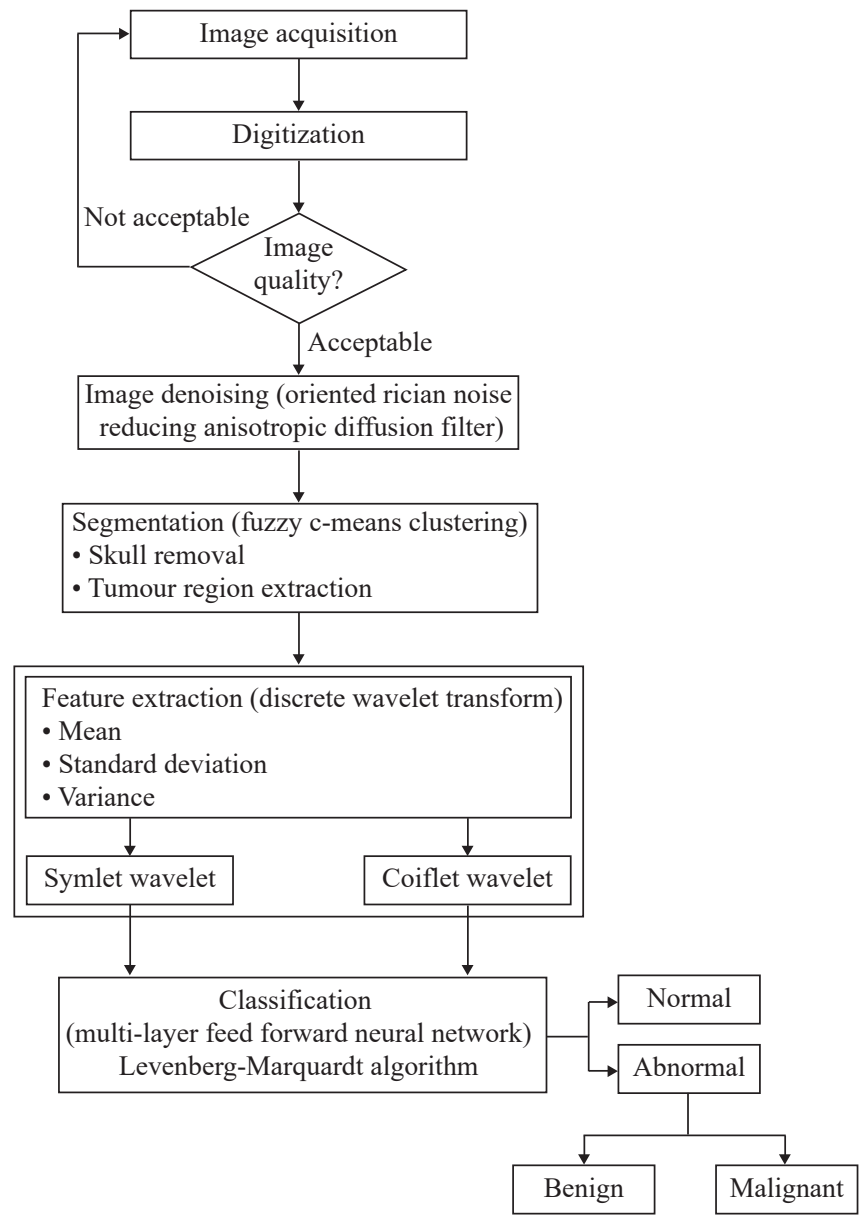

Fig. 1: Classification system for brain tumours.

The pre-processing starts with denoising which can be accomplished by various filters. Based on the performance of various filters, namely, hybrid median filter, linear minimum mean-square-error, oriented rician noise reduction anisotropic diffusion (ORNRAD), higher order hybrid median, and non-level means, the ORNRAD filter was found to perform well. Among the five top-quality parameters, namely, mean square error (MSE), peak signal to noise ratio (PSNR), contrast to noise ratio, image quality index and mean absolute error, MSE and PSNR values were considered to be more important to find the efficiency of filters. The ORNRAD filter resulted in an efficient reduction 
of noise while simultaneously preserving the detailed components and the high definition of the interface between various brain tissues.

The segmentation process was necessary to extract the testing area from the whole image by removing the skull region. In this work, fuzzy c-means clustering was used for segmentation. The partition of $\mathrm{n}$ elements $\mathrm{X}=$ $\{x 1, x 2, x 3, \ldots \ldots x n\}$ into a collection of c fuzzy clusters based on minimization was done in the following equation:

$$
J=\sum_{i=1}^{N} \sum_{j=1}^{c} u_{i j}^{m}\left|x_{i}-y_{i}\right|^{2}
$$

where ' $m$ ' is the parameter which controls the degree of clustering and ' $u$ ' represents the fuzzy membership of the given data. The efficiency of the fuzzy c-means algorithm was better for MR images when compared with other unsupervised algorithms. The similar patches were identified using the fuzzy c-means, and the unwanted information was removed from the denoised image.

The most important texture features were extracted using the discrete WT. It was used to extract the wavelet coefficients from MR images. The important features such as mean, standard deviation and variance were extracted from the segmented image. The characteristics of textures present in the MR images of the brain were analysed using wavelet-based feature extraction method. The MR images of the brain were then classified using a multi-layer feed forward (MLFF) neural network trained by a heuristic Levenberg-Marquardt (LM) algorithm.

\section{RESULTS}

The classification of MR images of the brain using WT and neural network was carried out using image processing tools. The acquired image was pre-processed and then features were extracted for further classification. The performance of the ORNARD filter was estimated and compared with various filters (Table 1) and was further used for validation and pre-processing.

Among the five parameters considered, MSE and PSNR were found to be important. The MSE was very low for the ORNRAD filter compared to other filters. The PSNR was also found to be on par with the other filters. Figure 2 shows the sample MR image and the output of the ORNRAD filter.

Further, the denoised image was subjected to segmentation. The tumour region was extracted using the fuzzy c-means clustering algorithm. Here, the similar patches were also identified as shown in Figure 3.
A test image was taken from a set of MR images of the brain and decomposed with two separate wavelets: symlet and coiflet. The symlet wavelet, which is an altered version of Daubechies wavelet, was chosen due to the increased symmetry. The coiflet wavelet is another wavelet with near symmetry and disappearing moments.

Table 1: Comparison of performance of various filters

\begin{tabular}{lccccc}
\cline { 2 - 6 } Filters & $\begin{array}{c}\text { Mean } \\
\text { square } \\
\text { error }\end{array}$ & $\begin{array}{c}\text { Peak } \\
\text { signal } \\
\text { to noise } \\
\text { ratio }\end{array}$ & $\begin{array}{c}\text { Contrast } \\
\text { to noise } \\
\text { ratio }\end{array}$ & $\begin{array}{c}\text { Image } \\
\text { quality } \\
\text { index }\end{array}$ & $\begin{array}{c}\text { Mean } \\
\text { absolute } \\
\text { error }\end{array}$ \\
\hline $\begin{array}{lccccc}\text { Hybrid median filter } \\
\text { Linear minimum }\end{array}$ & 47.6 & 31.42 & 53.23 & 0.935 & 2.97 \\
mean-square-error & 84.8 & 28.75 & 45.52 & 0.15 & 4.2 \\
$\begin{array}{l}\text { Higher order hybrid median } \\
\text { Non-level means }\end{array}$ & 85.6 & 29.02 & 45.35 & 0.88 & 3.62 \\
$\begin{array}{l}\text { Oriented rician noise } \\
\text { reduction anisotropic }\end{array}$ & 49.2 & 31.25 & 58.2 & 0.89 & 3.18 \\
diffusion & 30 & 33.35 & 52.56 & 0.92 & 1.25 \\
\hline
\end{tabular}

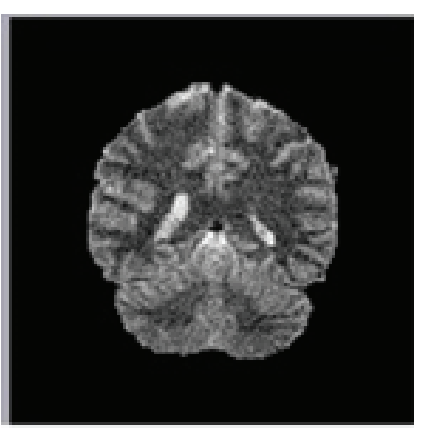

A: noisy image

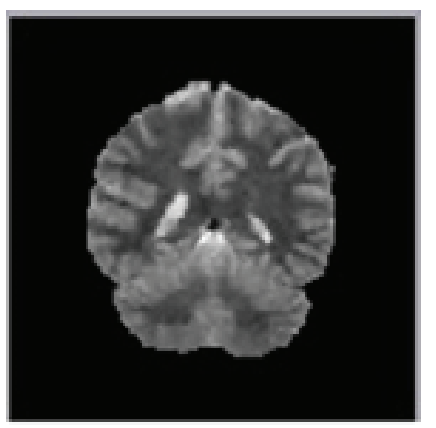

B: denoised image
Fig. 2: Noisy and denoised images using oriented rician noise reducing anisotropic diffusion filter.

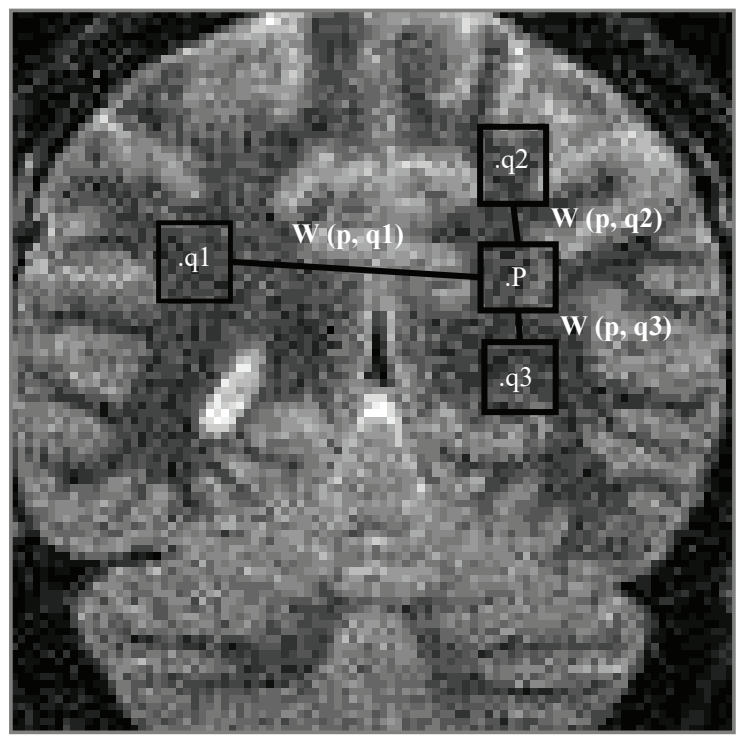

Fig. 3: Patch identification based on fuzzy c-means. 
The method was tested for 172 sets of MR images. Table 2 shows the performance measure of the symlet and coiflet wavelets for 10 sets of MR images.

Table 2: Performance measure for symlet and coiflet wavelets

\begin{tabular}{lcccccc}
\hline \multirow{2}{*}{$\begin{array}{l}\text { Test } \\
\text { image }\end{array}$} & \multicolumn{2}{c}{ Symlet (500 iterations) } & \multicolumn{3}{c}{ Coiflet (500 iterations) } \\
\cline { 2 - 7 } & $\begin{array}{c}\text { Gradient } \\
\text { value }\end{array}$ & $\begin{array}{c}\text { Regression } \\
\text { coefficient }\end{array}$ & $\begin{array}{c}\text { Tumour } \\
\text { accuracy } \\
\text { (\%) }\end{array}$ & $\begin{array}{c}\text { Gradient } \\
\text { value }\end{array}$ & $\begin{array}{c}\text { Regression } \\
\text { coefficient }\end{array}$ & $\begin{array}{c}\text { Tumour } \\
\text { accuracy } \\
\text { (\%) }\end{array}$ \\
\hline 1 & 0.439 & 0.675 & 94.25 & 0.0736 & 0.453 & 93.65 \\
2 & 0.0984 & 0.957 & 93.06 & 0.178 & 0.85 & 91.56 \\
3 & 0.542 & 0.569 & 93.03 & 0.193 & 0.438 & 92.12 \\
4 & 0.0973 & 0.963 & 93.05 & 0.084 & 0.86 & 91.62 \\
5 & 0.092 & 0.956 & 92.11 & 0.087 & 0.872 & 90.52 \\
6 & 0.437 & 0.62 & 92.26 & 0.372 & 0.514 & 91.03 \\
7 & 0.648 & 0.593 & 93.83 & 0.127 & 0.486 & 92.8 \\
8 & 0.73 & 0.732 & 94.52 & 0.28 & 0.452 & 92.84 \\
9 & 0.042 & 0.762 & 93.66 & 0.053 & 0.673 & 92.6 \\
10 & 0.091 & 0.92 & 92.62 & 0.072 & 0.852 & 90.12 \\
\hline
\end{tabular}

For the test image set 1 , the regression coefficient for the symlet wavelet was 0.675 and 0.453 for the coiflet wavelet (Table 2). For the second set, it was 0.957 and 0.85 . Likewise, the regression coefficient for the symlet wavelet was marginally higher than that for the coiflet wavelet. It was observed that the gradient value of the symlet wavelet was on par with that of the coiflet wavelet. The accuracy of the tumour region extraction was also marginally higher for the symlet wavelet when compared to the coiflet wavelet. So, the performance of the symlet wavelet was slightly better than that of the coiflet wavelet.
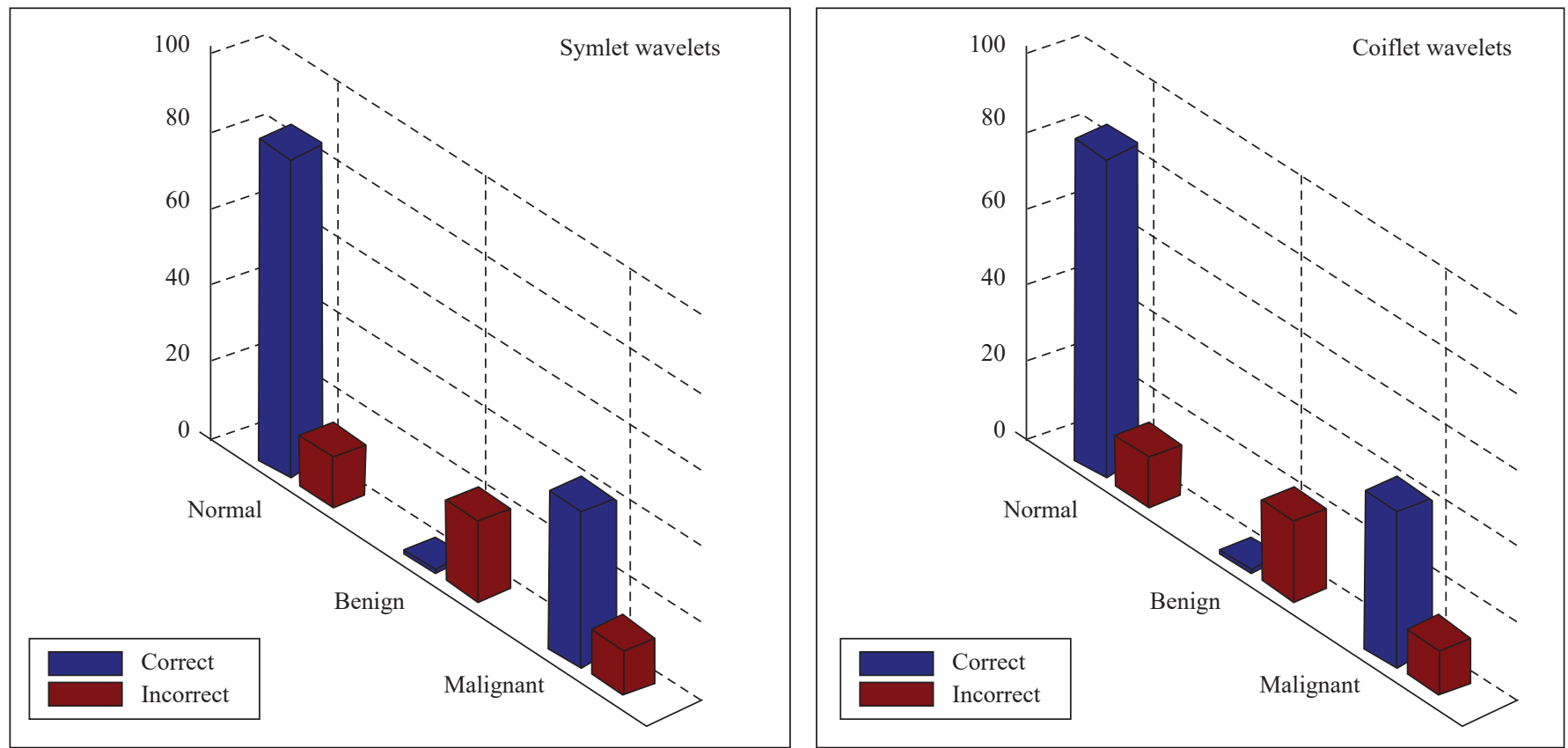

The outputs of the wavelets were trained through MLFF neural network based on LM algorithm for the prediction of the severity of the tumour growth. A threelayered neural network (one input layer, a hidden layer and an output layer) was used for the decision-making. Five neurons were considered in the input layer. For the hidden layer, one to five nodes could be used, and one node was considered for the output layer. The training required 500 iterations for the exact decision of the severity of the tumour. The time required for each iteration was around 0.06 second using the LM algorithm.

\section{DISCUSSION}

The predictive analysis was given in terms of three classes: normal, benign and malignant. Figure 4 shows the classification accuracies of MR images of the brain using symlet wavelet and coiflet wavelet. It was observed that the number of correct classifications was greater than the number of incorrect classifications. The percentages of prediction accuracy were estimated to be $93.24 \%$ and $91.89 \%$ respectively. It was inferred from the analysis that symlet wavelet-based classifier provided a better classification for MR images of the brain.

Table 3 shows the classification accuracies obtained using various methods. It was observed that the performance of the present method was satisfactory compared to the other existing classification methods of brain tumours. The classification accuracies of the previous methods can be clearly viewed from Table 3 .

Fig. 4: Classification accuracy of neural network classifier using symlet and coiflet wavelets. 
Table 3: Comparative analysis of classification accuracies obtained by various methods

\begin{tabular}{|c|c|c|c|}
\hline \multirow[t]{2}{*}{ Author } & \multicolumn{2}{|r|}{ Technique used } & \multirow{2}{*}{$\begin{array}{l}\text { Classification } \\
\text { accuracy }(\%)\end{array}$} \\
\hline & Feature extraction & Classification & \\
\hline Huml et al (12) & Genetic programming & (Single feature) & 89.38 \\
\hline Razek et al (13) & Dynamic susceptibility contrast & Analysis of variance test & 84.60 \\
\hline Zacharaki et al (14) & Gabor filter & Binary support vector machine & 85.00 \\
\hline Rajalakshmi and Prabha (15) & Wrapper approach & Multi-class support vector machine & 89.17 \\
\hline Naik and Patel (16) & Grey level co-occurrence matrix & Naïve Bayes & 88.20 \\
\hline Jafari and Shafaghi (17) & Genetic algorithm & Support vector machine & 83.22 \\
\hline Current study & $\begin{array}{l}\text { Symlet wavelet } \\
\text { Coiflet wavelet }\end{array}$ & $\begin{array}{l}\text { Multi-layer feed forward neural network based on Levenberg- } \\
\text { Marquardt algorithm }\end{array}$ & $\begin{array}{l}93.24 \\
91.89\end{array}$ \\
\hline
\end{tabular}

It was observed that the previous methods had been based on various classifiers and filters, and the accuracy was identified to be around $80-90 \%$. From this, it is clear that the present method provided improved accuracy which is useful for physicians' clinical decision-making. It was observed that symlet wavelet performed better than coiflet wavelet in terms of classification accuracy and regression. Future work involves the reduction of computation and processing time of image classification using parallelization techniques.

\section{REFERENCES}

1. Johnson KJ, Cullen J, Barnholtz-Sloan JS, Ostrom QT, Langer CE, Turner MC et al. Childhood brain tumor epidemiology: a brain tumor epidemiology consortium review. Cancer Epidemiol Biomarkers Prev 2014; 23: 2716-36.

2. Celik T, Tjahjadi T. Multiscale texture classification using dual-tree complex wavelet transform. Pattern Recogn Lett 2009; 30: 331-9.

3. Akansu N, Haddad RA, Caglar H. The binomial QMF-wavelet transform for multiresolution signal decomposition. IEEE Trans Signal Process 1993; 41: 13-9.

4. Zhang Y, Wang S, Wu L. A novel method for magnetic resonance brain image classification based on adaptive chaotic PSO. Prog Electromagn Res 2010; 109: 325-43.

5. Krissian K, Aja-Fernández S. Noise-driven anisotropic diffusion filtering of MRI. IEEE T Image Process 2009; 18: 2265-74.

6. Anand CS, Sahambi JS. Wavelet domain non-linear filtering for MRI denoising. J Magn Reson Imaging 2010; 28: 842-61.

7. Jaya J, Thanushkodi K, Karnan M. Tracking algorithm for de-noising of MR brain images. Int J Computer Sci Network Security 2009; 9: 262-7.
8. Yang MS, Lin KC, Liu HC, Lirng JF. Magnetic resonance imaging segmentation techniques using batch type learning vector quantization algorithms. J Magn Reson Imaging 2007; 25: 265-77.

9. Bacauskiene M, Verikas A, Gelzinis A, Valincius D. A feature selection technique for generation of classification committees and its application to categorization of laryngeal images. Pattern Recognit 2009; 42: 645-54.

10. Svolos AE, Todd-Pokropek A. Time and space results of dynamic texture feature extraction in MR and CT image analysis. IEEE Trans Inf Technol Biomed 1998; 2: 48-54.

11. Mahmood AF, Abd-Alsalam AM. Automatic brain MRI slices classification using hybrid technique. Al-Rafidain Engineering 2014; 22: 198-212.

12. Huml M, Silye R, Zauner G, Hutterer S, Schilcher K. Brain tumor classification using AFM in combination with data mining techniques. Biomed Res Int 2013; 2013: 1-11.

13. Razek AAKA, Elsorogy LG, Soliman NY, Nada N. Dynamic susceptibility contrast perfusion MR imaging in distinguishing malignant from benign head and neck tumors: a pilot study. Eur J Radiol 2011; 77: 73-9.

14. Zacharaki EI, Wang S, Chawla S, Soo Yoo D, Wolf R, Melhem ER et al. Classification of brain tumor type and grade using MRI texture and shape in a machine learning scheme. Magnet Reson Med 2009; 62: 1609-18.

15. Rajalakshmi N, Prabha VL. Automated classification of brain MRI using color converted K-means clustering segmentation and application of different kernel functions with multi-class SVM. Eur Sci J 2013; 9: 799-806.

16. Naik J, Patel S. Tumor detection and classification using decision tree in brain MRI. Int J Eng Dev Res 2013; 1: 49-53.

17. Jafari M, Shafaghi R. A hybrid approach for automatic tumor detection of brain MRI using support vector machine and genetic algorithm. Glo J Sci Eng Tech 2012; 3: 1-8. 